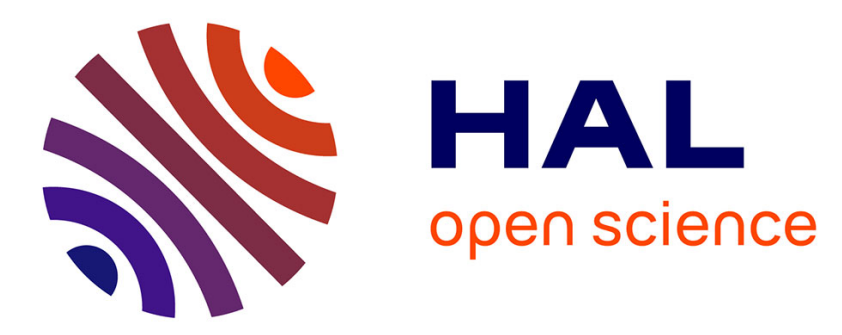

\title{
Impact damage prediction in thin woven composite laminates-Part I: Modeling strategy and validation
}

Florian Pascal, Olivier Dorival, Pablo Navarro, Steven Marguet, Jean-François Ferrero

\section{- To cite this version:}

Florian Pascal, Olivier Dorival, Pablo Navarro, Steven Marguet, Jean-François Ferrero. Impact damage prediction in thin woven composite laminates-Part I: Modeling strategy and validation. Composite Structures, 2018, 190, pp.32 - 42. 10.1016/j.compstruct.2018.02.007 . hal-01878006

\section{HAL Id: hal-01878006 https://hal.science/hal-01878006}

Submitted on 20 Sep 2018

HAL is a multi-disciplinary open access archive for the deposit and dissemination of scientific research documents, whether they are published or not. The documents may come from teaching and research institutions in France or abroad, or from public or private research centers.
L'archive ouverte pluridisciplinaire HAL, est destinée au dépôt et à la diffusion de documents scientifiques de niveau recherche, publiés ou non, émanant des établissements d'enseignement et de recherche français ou étrangers, des laboratoires publics ou privés. 


\title{
Impact damage prediction in thin woven composite laminates - Part I: Modeling strategy and validation
}

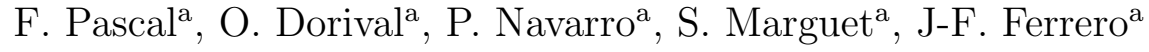 \\ ${ }^{a}$ Université de Toulouse, Institut Clément Ader, FRE CNRS 3687, \\ UPS/INSA/ISAE/Mines Albi, 3 rue Caroline Aigle, 31400 Toulouse, France
}

\begin{abstract}
An explicit finite element modeling of the 5-harness satin woven composite material is proposed in this paper. It is based on the semi-continuous approach. The bundles are modeled with rod elements and a specific damageable shell element is used to stabilize this truss structure. As the woven pattern geometry plays a key role in damage initiation and propagation, the rods located at the crimp regions where warp and weft yarns cross each other have been offset to represent the bundles undulations. The main objective of the presented modelling strategy is to represent local bending stiffness variations and damage initiation at the crimp regions without using artificial parameters, but only geometric and material parameters.

The method has been implemented into the explicit finite element code RADIOSS. The modeling strategy is validated by representing a three-point bending test and a drop weight test. It provides good prediction for the local bending stiffness, the impact force history and the damage size and shape. The strain concentration at the crimp regions is well represented.

Keywords: Woven fabric composite, 5-harness satin, Damage, Impact, Explicit F.E modeling
\end{abstract}




\section{Introduction}

This article deals with the modeling of impact damage within woven composite laminates. Woven composite materials are being widely used in automotive and aeronautical industries. Indeed, compared to the unidirectional composites, they offer a higher capacity to drape complex geometries, a greater interlaminar fracture toughness [1] and a better damage tolerance for impact loading $[2,3]$. This low-weight and high-strength material is often used to manufacture thin laminate structures with two or three plies, that are mostly skins of sandwich structures (helicopter blades for instance). In such cases, a low velocity impact onto the structure generates a dynamic bending load that can involve all the damage mechanisms namely the matrix cracking, the delamination and the fibre failures. Since it can entail catastrophic consequences, understanding and predicting all those mechanisms is required.

The characteristic structure of woven composite materials highly influences damage mechanisms $[4,5,6]$. Indeed, the damage first appears in the region where the yarns cross each other : the crimp region. More, Nilakantan et al. [7] showed that the local variation of the strength of the yarns can have a major effect on the impact response of woven fabrics.

In the specific field of impacts on woven fabric composites, five main modeling strategies can be highlighted.

The first one consists in developing analytical modeling based mainly on the balance between the impact energy, the dissipated energy and the post-impact kinetic energies [8,9]. Even if these analytical models provide a very good approximation of the damage level, more precise prediction of 
the damage in more complex composite structures is sometimes needed, in order to predict the post-impact behavior or to analyze with more accuracy the impact behavior, for instance.

The second one consists in using FEM with customized damageable energy based material laws $[10,11,12]$. In these models, the woven fabric is represented using homogenized shell elements.

In the third main strategy, the developed woven composite models are based on continuum properties calculated from a deforming unit cell [13, 14, 15, 16]. This unit cell can be a very detailed three-dimensional pattern of the woven fabric [17] or it can be represented with a specific truss structure [18]. This strategy is able to represent the local strain and stress fields due to the weaving pattern, but it can hardly be used for large structures.

These last three strategies rely on the assumption that at an appropriate scale, the woven fabric behaves homogeneously and thus it can be approximated as a continuum. This assumption is no longer available when damage occurs.

Thus, a fourth strategy based on FEM, presented by Johnson et al. [19] consists in modeling each woven lamina with a three-dimensional damaging non-linear orthotropic material connected with cohesive elements. This strategy provides good prediction of delamination area and contact forcetime history for low velocity impacts. Nevertheless, this strategy requires a large number of elements, which can be prohibitive for the modeling of representative structures.

Finally, a fifth strategy has been proposed in [20]. It is based on experimental observations of medium velocity tests [21]. When the resin is totally 
damaged, the woven fabric behaves like a discrete truss structure. A semicontinuous approach, where specific damageable shell elements are coupled with rod elements, was developed. More recently, the strategy was improved by taking into account the weaving pattern influence on the damage scenario [22]. The idea was to adapt the material properties of the rods located at the crimp region in order to represent local strain concentrations. This material approach provides a good representation of the damage mechanisms over low-to-medium velocity impact loading, for thin composite structures made of two or three plies.

Nevertheless, this last strategy presents two main limitations. First of all, local strain concentrations are represented by the introduction of two parameters used to lower artificially the failure strain in the crimp regions. The value of these parameters can not be directly calculated from simple tests and are chosen by making a compromise between numerical and experimental results.

The second limitation of this modelling strategy concerns the local bending stiffness variations of thin woven composite laminates. Indeed, given that thin woven composite laminates are mainly subjected to flexural loading during impacts, bending behavior has been investigated. Thus, three point bending tests have been performed. The particular geometry of the 5-harness satin weave pattern provides to the woven ply a face where the tows are mostly oriented at $0^{\circ}$ while the tows of the other face are mostly oriented in the perpendicular direction at $90^{\circ}$. When two plies are stacked together, two configurations can be distinguished as illustrated in Fig. 1 if the tows are (a) asymmetrically or (b) symmetrically positioned with respect 
to the neutral axis of the laminate.

These two laminate configurations are tested on a three-points bending test to evaluate their flexural behaviors for each local fabric direction $(0 / 90)^{\circ}$ for the carbon/epoxy material. The experimental set up is presented on Fig. 2. The loading is carried out with three $6 \mathrm{~mm}$ diameter cylinders. The two bottom cylinders are fixed and positioned with a gap of $8 \mathrm{~mm}$. The velocity of the top cylinder is set to $1 \mathrm{~mm} . \mathrm{min}^{-1}$. The specimens are $60 \mathrm{~mm}$ long, $20 \mathrm{~mm}$ wide and about $0.72 \mathrm{~mm}$ thick.

In order to minimize the influence of the thickness on the experimental result analysis, the maximal bending stress is plotted versus the maximal bending strain by regarding the material as homogeneous with:

$$
\varepsilon_{\max }^{f}=\frac{6 h}{L^{2}} d \quad ; \quad \sigma_{\max }^{f}=\frac{3 L}{2 b h^{2}} F
$$

where $h$ is the thickness of the laminate, $L$ the length, $b$ the width, $d$ the measured deflection of the specimen and $F$ the measured force. The curves are showed in Fig. 3.

A significant difference in the bending stiffness is observed. For an asymmetrical configuration (curves 1 and 2), the local bending stiffness in the $0^{\circ}$ or $90^{\circ}$ directions are very close and are about 36-40 MPa. Concerning the symmetrical configuration, compared to the asymmetrical one, the bending stiffness is $30 \%$ lower at $0^{\circ}$ (curve 3 ) and $70 \%$ higher at $90^{\circ}$ (curve 4 ). This phenomenon is due to the position of the tows in the laminate thickness direction which carry more or less the load in function of their distance from the neutral axis. It involves an increase of $150 \%$ of the bending stiffness between the two local fabric directions. This bending stiffness variation can not be represented with the Semi-Continuous Modelling presented in [22], as 
in this modelling the bending stiffness is the same for each element.

In this paper, another strategy is described to represent the weaving pattern influence, still based on the semi-continuous modeling, but this time with a geometrical approach. Indeed, in the proposed strategy, the woven pattern is explicitly represented by offsetting the rods. The first objective is to improve the representation of the local bending behavior of the woven composite laminate during impact loading. The second objective is to represent local strain concentrations at crimp regions without using artificial parameters, but only geometric and material parameters.

In the first part of this paper, the modeling strategy is described. In the second part, the proposed strategy is validated by comparing the numerical results with experimental results provided by three point bending tests and low velocity impact tests.

This modeling is able to capture the good bending stiffness of any woven laminate stratification and to well predict the damage size induced by drop weight impact tests onto thin 5-harness carbon/epoxy woven laminates.

\section{Modelling strategy}

\subsection{Woven ply modelling}

The modeling strategy of the ply proposed in this paper is presented in Fig. 4 through the representation of a 5 -harness satin woven composite. The principle is to model the woven fabric bundles with a truss structure which follows the woven pattern geometry. The mesh size respects the woven fabric pattern i.e. the distance between two bundles. The interlacing of the warp and the weft tows at the crimp regions is then approximated with oblique rod 
elements. The epoxy matrix which embed the fibre bundles is modeled with damageable shell elements placed at the neutral axis of the ply. The nodes of the rods are offset from the shell to a distance of $h / 4$ in the thicknessdirection where $h$ is the ply thickness. Finally, the connection between the rods and the shell elements is realized at the nodes through rigid links as exposed at the bottom-right side of Fig. 4. Thus, the rotational degrees of freedom of the shell induce the tension and compression of the rods.

This strategy allows to both represent the continuous elastic behavior of the undamaged ply and the discrete behavior of the woven ply when resin is damaged and fibre bundles are in a non-stabilized state.

\subsubsection{Implementation}

In order to mesh the satin weave pattern geometry, five fundamental element configurations (Fig. 5a) are needed: one element which allows to mesh the standard region where there is no interlacing of tows and four elements numbered 2 to 5 which can be assembled to represent the crimp

region by crossing the rods i.e. the warp and the weft tows. The meshing of the 5-harness satin weave pattern is thus illustrated in Fig. 5b.

\subsubsection{Rod formulation}

The rod elements which represent the tows behave as an elastic material. The bundle rupture is assumed to be brittle in tension. Therefore, a classic maximum tensile strain criterion is used for the rupture of the rods. In order to avoid numerical instabilities, when the maximum strain criterion is reached, rod normal force is smoothly decreased by the use of a characteristic 
time $\tau$ as follow:

$$
F_{11}=F_{11}^{*}\left(1-\exp \frac{t^{*}-t}{\tau}\right),
$$

where $t^{*}$ is the exact time at which the criterion is reached and $F_{11}^{*}$ the force stored at time $t^{*}$.

The final failure is reached when $F_{11}=0.1 F_{11}^{*}$. This law is plotted in Fig. 6. $\tau$ has been taken equal to $1 \mu s$ which corresponds to the best compromise between stability and parameter sensitivity to the results. The compression failure mechanism i.e. kink band phenomenon is neglected in this study.

\subsubsection{Shell formulation}

The developed shell element which represents the epoxy resin material is based on a Batoz Q4 $\gamma 24$ shell formulation [23] with four Gauss integration points and a reduced integration for in-plane shear. No hourglass control is needed for this shell. The mechanical behavior implemented in the shell is an isotropic elastic behavior with an anisotropic damage formulation. The idea is to represent the first cracks observed experimentally that are parallel to the bundles. Thus, matrix failure is modeled with two damage variables, namely $d_{1}$ and $d_{2}$, for each local fabric direction (warp and weft directions). The value of these two variables is comprised between 0 , when there is no damage, and 1, when the crack size is maximum. The membrane, bending and shear stiffness matrix are thus defined by: 


$$
\left\{\begin{array}{c}
\sigma_{11} \\
\sigma_{22} \\
\sigma_{12} \\
\sigma_{13}
\end{array}\right\}=\left[\begin{array}{ccccc}
\frac{\left(1-d_{1}\right) E}{1-\left(1-d_{1}\right)\left(1-d_{2}\right) \nu^{2}} & \frac{\left(1-d_{1}\right)\left(1-d_{2}\right) \nu E}{1-\left(1-d_{1}\right)\left(1-d_{2}\right) \nu^{2}} & 0 & 0 & 0 \\
\frac{\left(1-d_{1}\right)\left(1-d_{2}\right) \nu E}{1-\left(1-d_{1}\right)\left(1-d_{2}\right) \nu^{2}} & \frac{\left(1-d_{2}\right) E}{1-\left(1-d_{1}\right)\left(1-d_{2}\right) \nu^{2}} & 0 & 0 & 0 \\
0 & G_{12} & 0 & 0 \\
0 & 0 & 0 & \left(1-d_{1}\right) G_{13} & 0 \\
0 & 0 & 0 & 0 & \left(1-d_{2}\right) G_{23}
\end{array}\right]\left\{\begin{array}{c}
\varepsilon_{11}^{m} \\
\gamma_{12}^{m} \\
\varepsilon_{23}^{m} \\
\gamma_{13}^{m} \\
0
\end{array}\right.
$$

where $E$ is the elastic Young modulus, $\nu$ the in-plane Poisson's ratios and $G_{i 3}$ the out-of-plane shear moduli.

The parameters $d_{1}$ and $d_{2}$ are functions of the energy release rates $Y_{1}$ and $Y_{2}$ calculated from the resin material elastic properties. Damage evolution is given by:

$$
d_{i}=\left\{\begin{array}{cc}
\frac{\left\langle\sqrt{Y_{i}}-\sqrt{Y_{0}}\right\rangle_{+}}{\sqrt{Y_{c}}} & \text { if } d_{i}<1 \\
1 & \text { otherwise }
\end{array} \quad(i=1,2)\right.
$$

where $Y_{0}$ controls the damage initiation, $Y_{c}$ the damage evolution. The energy release rate $Y_{i}$ regarding the local direction $i$ is given by:

$$
Y_{i}=\sup _{t \leq \tau}\left(\frac{E}{2\left(1-\nu^{2}\right)}<\varepsilon_{i i}^{m}+\varepsilon_{i i, \text { max }}^{b}>_{+}^{2}\right) \quad(i=1,2),
$$

with $<\varepsilon_{i i}^{m}+\varepsilon_{i i, \max }^{b}>_{+}$which denotes the positive part of the sum of the membrane and the maximum positive bending strains in local direction $i=$ 1,2 and $\nu$ the matrix in-plane elastic Poisson's ratio. 
Hence, $d_{1}$ and $d_{2}$ manage all the mechanical variable of the shell except for the in-plane shear modulus $G_{12}$. Indeed, it has been observed experimentally that pseudo-plasticity was the predominant phenomenon concerning in-plane shear. Thus, a plastic strain $\gamma_{12}^{p}$ has been introduced. A classic elastic prediction and plastic correction based on a Newton-Raphson iterative scheme has been implemented. The elastic field is defined by:

$$
f=\left|\sigma_{12}\right|-K_{\text {plas }}\left(\varepsilon_{12}^{p}\right)^{B}-\sigma_{0},
$$

where $\sigma_{12}$ is the in-plane shear stress, $\sigma_{0}$ the plastic strength, $\varepsilon_{12}^{p}$ the plastic shear strain and $\left(K_{\text {plas }}, B\right)$ are material parameters defining the plastic hardening law.

Besides, a third independent damage variable $d_{12}$ has been implemented to model the final in-plane shear rupture. Its evolution is driven by a brittle law:

$$
d_{12}=\left\{\begin{array}{ll}
0 & \text { if } \quad \gamma_{12}^{p}<\gamma_{\max }^{p} \\
1 & \text { if } \quad \gamma_{12}^{p} \geq \gamma_{\max }^{p}
\end{array},\right.
$$

where $\gamma_{\max }^{p}$ is the in-plane shear plastic strain to rupture.

The material parameters of the 5-harness satin carbon-epoxy woven fabric have been identified with the same approach that was used in [21] which was concerned with the 8-harness satin glass-epoxy woven fabric. The matrix modulus $E$ is a material property given by the fabric's manufacturer. Then, quasi-static and dynamic tests on $(0 / 90)^{\circ}$ and $\pm 45^{\circ}$ oriented specimens have been performed. The other parameters are thus determined with a reverse engineering method which consists in minimizing the difference between experimental and computed load/displacement curves. The evolution of the damage variables $\left(d_{1}, d_{2}\right)$ has been calculated from static and dynamic in- 
dentation tests. The identified parameters for the shell elements are given in Table 1.

\subsection{Woven laminate modelling}

The object of this part is to define a strategy to represent the laminate skin from the model of a single woven ply presented above. The idea is to use a specific element to connect the plies. Using a "classic" 8-node solid element with three translational degrees of freedom per node is inappropriate. Indeed, as the rotational degrees of freedom of the connected shells cannot be transmitted, the bending stiffness of the laminate is not representative. More, as the interface is connected directly to the mid-surface of the specific shells, part of the material represented by this 8-node solid element is superfluous. One direct consequence is the difficult identification of the material properties for the interface: the stiffness value cannot be simply deduced from the material properties of the resin. In order to solve these two problems, a shell-to-shell 8-node interface element has been developed.

The main idea is to use a cohesive zone strategy at the real surface of the composite ply. To do so, in addition to the three translational degrees of

freedom, the nodes of the developed element have three rotational degrees of freedom which allow a feasible connection to shell elements. The idea is to take into account the thickness of the connected plies. Eight virtual nodes are created at the real surfaces of these plies (Fig. 7). The assumption is made that the straight lines normal to the mid-surface of the plies remain normal to the mid-surface, that is to say the Kirchhoff-Love hypothesis is assumed. Thus, the virtual nodes are considered to be connected to the real nodes with rigid body elements (Fig. 7). The deformed configuration of the 
virtual cohesive element due a rotation of the woven shell element nodes is illustrated in Fig. 8. In a first approach the out of plane straining of each ply, due to Poisson effects, has been neglected $\left(\varepsilon_{z z}=0\right)$. The reaction forces and momentum applied to the real nodes are deduced from the reaction forces applied on the virtual nodes.

The interlaminar connection is modeled using a bilinear cohesive law as described in $[24,25,26,27]$. The interface is considered as a thin layer separating the plies in which the damage mechanisms leading to delamination are localized. The out of plane stresses $\left(\sigma_{x z}, \sigma_{y z}, \sigma_{z z}\right)$ are calculated using a traction-separation law:

$$
\left\{\begin{array}{c}
\sigma_{x z} \\
\sigma_{y z} \\
\sigma_{z z}
\end{array}\right\}=K\left\{\begin{array}{c}
\delta_{x} \\
\delta_{y} \\
\delta_{z}
\end{array}\right\}
$$

Where $\delta_{x}$ and $\delta_{y}$ correspond to sliding displacement discontinuities (mode II and mode III) and $\delta_{z}$ to an opening displacement discontinuities (mode I) as illustrated in Fig. $9 . K$ is the stiffness of the interface calculated from the young modulus of the resin $E$ and the theoretical thickness of the interface $e_{\text {int }}$.

$$
K=\frac{E}{e_{i n t}} \quad \text { with } \quad e_{i n t}=\frac{e_{p l y}}{5}
$$

The behaviour is supposed to be similar in pure mode II and mode III loading. In the following, mode II refers to mode II and mode III. The decohesion process starts when:

$$
\left(\frac{\sigma_{I}}{\sigma_{I}^{\max }}\right)^{2}+\left(\frac{\sigma_{I I}}{\sigma_{I I}^{\max }}\right)^{2} \geq 1
$$


Where $\sigma_{I}=\left\langle\sigma_{z z}\right\rangle_{+}$and $\sigma_{I I}=\sqrt{\sigma_{x z}^{2}+\sigma_{y z}^{2}} \cdot \sigma_{I}^{\max }$ and $\sigma_{I I}^{\max }$ correspond respectively to the stress thresholds in mode I and in mode II. Thus the sliding displacement for initiation $\delta_{0}$ is calculated:

$$
\begin{gathered}
\delta^{0}= \begin{cases}\delta_{I}^{0} \delta_{I I}^{0} \sqrt{\frac{1+\beta^{2}}{\left(\delta_{I I}^{0}\right)^{2}+\left(\beta \delta_{I}^{0}\right)^{2}}}, & \text { if } \delta_{I}>0 \\
\delta_{I I}^{0}, & \text { otherwise }\end{cases} \\
\beta=\frac{\delta_{I I}}{\delta_{I}}
\end{gathered}
$$

Where $\delta_{I}^{0}$ and $\delta_{I I}^{0}$ are the pure mode I and II displacement threshold that correspond to the two stresses $\sigma_{I}^{\max }$ and $\sigma_{I I}^{\max }, \delta_{I}=\delta_{z}$ and $\delta_{I I}=\sqrt{\delta_{x}^{2}+\delta_{y}^{2}}$.

The total failure is reached when:

$$
\frac{G_{I}}{G_{I c}}+\frac{G_{I I}}{G_{I I c}}=1
$$

Where $G_{I}$ and $G_{I I}$ are the current energy release rates. $G_{I c}$ and $G_{I I c}$ correspond respectively to the critical strain energy release rate in mode I and in mode II. From this failure criterion, a critical sliding displacement $\delta^{c}$ can be calculated:

$$
\delta^{c}= \begin{cases}\frac{2\left(1+\beta^{2}\right)}{K \delta^{0}}\left(\frac{1}{G_{I c}}+\frac{\beta^{2}}{G_{I I c}}\right)^{-1}, & \text { if } \delta_{I}>0 \\ \frac{2 G_{I I c}}{K \delta^{0}}, & \text { otherwise }\end{cases}
$$

Finally, during the unloading phase, the stresses reduce linearly (Fig. 10).

The damage parameters of the interface are identified from two tests of interlaminar crack propagation: a pure mode I Double Cantilever Beam (DCB) test, and a pure mode II End-Notched Flexure (ENF) test. Identified values are given in Table 2 . 


\section{Validation and discussion}

In this section, the capacity of the modeling strategy to predict the behavior of a laminate made of two plies of 5-harness satin carbon/epoxy woven composite is investigated upon two tests: a three-point-bending test and a drop weight normal impact test.

\subsection{Bending behaviour validation}

Since a thin woven composite laminate is mainly subjected to flexural loading during a low velocity impact, three-points-bending tests have been performed to evaluate the capacity of the modeling approach to recover the good bending stiffness response. The experimental set up and the experimental results were presented in the introduction.

A modeling of this test, relying on the strategy presented in section 2 , is proposed (Fig. 11). Each specimen is modeled in accordance with its stacking sequence for ensuring the well repartition of the tows in the laminate thickness given by the 5 -harness satin weave pattern geometry. The cylinders are represented with rigid walls and a mesh size of $1.4 \mathrm{~mm}$ is used for the virtual specimen which corresponds to the carbon/epoxy woven elementary mesh size.

The comparison between the experimental and the numerical results are showed in Fig. 12 for each local fabric direction of each stacking sequence configuration. The good agreement between the experimental and the numerical curves shows that the proposed strategy is able to capture the good bending stiffness for each specimen with a maximal relative error of $10.4 \%$. This result is due to the well representation of the woven geometry and the 
well repartition of the rods in the thickness direction of the laminate.

\subsection{Drop weight impact test validation}

\subsubsection{Experimental set up}

Four drop weight impact test have been conducted onto a single ply of carbon-epoxy 5-harness satin woven composite. The specimen dimensions are $100 \times 100 \times 0.36 \mathrm{~mm}$. The woven ply is positioned on a rigid support with a $30 \mathrm{~mm}$ diameter circular hole as illustrated on Fig. 13. The steel impactor has a $20 \mathrm{~mm}$ diameter hemispheric shape and a mass of $2 \mathrm{~kg}$. It impacts the specimen with an initial velocity of $3 \mathrm{~m} / \mathrm{s}$, that is to say with an impact energy of $9 \mathrm{~J}$. The reaction force and the displacement of the impactor are recorded during impact. At last, the bottom face of the specimen is filmed with a high-speed digital camera (Photron FastCam APX RS) at a frame rate of $36,000 \mathrm{fps}$ and a resolution of $512 \times 128$ pixels. Three specimens are impacted in order to check the reproducibility of the experimental protocol.

\subsubsection{Experimental Results}

The experimental load versus displacement curve is illustrated on Fig. 14. The image sequences extracted from the high speed camera recording allow to identify five points on the curve that represent the damage scenario.

The first matrix crack is observed for a load value of $190 \mathrm{~N}$ (point A). On A-B-C path, the visible matrix cracks propagate in tows direction following the woven pattern. After reaching a pick load of $870 \mathrm{~N}$, the first fibre failure is observed at point $\mathrm{C}$ and concerned a weft tow. This macro crack quickly propagate in a cross or "L" shape. The load highly decreases to $200 \mathrm{~N}$. On D-E path, the macro crack propagates with a slightly decreasing load until 
the final perforation of the ply.

A damage scenario is then proposed from experimental observations. The first fibre failure is located at a crimp region as illustrated on Fig. 15. This assumption can be justify by the fact that the tows are highly waved and consequently more stressed in those regions. The macro crack propagates along the warp tows by the failure of the bundles in the weft direction. The crack finally propagates from one crimp region to another which creates the final 'L' shape crack.

\subsubsection{Numerical Results}

A modeling of this test, relying on the strategy presented in Section 2, is proposed. The specimen involves 14,000 user developed finite elements for a total of 48,000 dofs. The boundary conditions are introduced by the use of a contact between the specimen and a rigid wall. The impactor is a rigid sphere with the adequate mass and initial velocity. The mesh size is $1.4 \times 1.4 \mathrm{~mm}$ in agreement with the measured woven fabric pattern. All the computations are performed with the explicit finite element code RADIOSS on 20 cores from HPC resources. Time calculation is about $45 \mathrm{mins}$.

The experimental and numerical load versus displacement curves are compared in Fig. 16. As a first observation, the modeling gives a satisfactory estimation of the force signal. The numerical peak force and the final drop are in good agreement with the experimental results.

The fibre damage evolution for both test and modeling is then illustrated in Fig. 17. The different time steps correspond to the points C,D and E of the load versus displacement curve in Fig. 16. The respect of the woven geometry allows to be in good agreement with the damage scenario. The first failure is 
observed in the weft bundle of fibres (point C). The crack propagates along the warp and the weft direction to create an "L" shape (point D) then a "T" shape (point D). The final crack is very similar to the experimental one with a relative error on the crack length lower than 15 percent.

Finally, the first fibre failure is analyzed in Fig. 18. The crimp region is highly stressed just before the first fibre failure as observed in the analysis of the rod stress. The simplified geometry of the woven pattern is enough to represent the good scenario.

\section{Conclusion}

This article presents a Finite Element Modeling of a 5-harness satin woven composite material based on the semi-continuous approach. The bundles are represented with rod elements that are offset to represent the woven pattern geometry, and stabilized with specific shell elements. This strategy is validated by a comparison with three point bending tests and low velocity impact tests. The calculated load-displacement curves and the damage extent correlate well with experimental results.

The originality of this modeling is that the damage scenario, that initiates generally in the crimp region, can be represented only by offsetting rod elements, without varying locally the damage parameters of the elements. More, the bending stiffness variations observed for a two plies laminate, that depends on the position of the plies is accounted for when using the proposed strategy, which is not the case for other finite element models based on plate elements. 


\section{Acknowledgement}

The authors acknowledge the supercomputing centre CALMIP for granting access to the HPC resources under the allocation 2016-P09105.

\section{References}

[1] J. G. Funk, J. W. Deaton, The Interlaminar Fracture Toughness of Woven Graphite/Epoxy Composites., Tech. rep. (Nov. 1989).

[2] J.-K. Kim, M.-L. Sham, Impact and delamination failure of woven-fabric composites, Composites Science and Technology 60 (5) (2000) 745-761. doi:10.1016/S0266-3538(99)00166-9.

[3] N. K. Naik, Y. Chandra Sekher, S. Meduri, Damage in woven-fabric composites subjected to low-velocity impact, Composites Science and Technology 60 (5) (2000) 731-744. doi:10.1016/S0266-3538(99)00183-9.

[4] S. V. Lomov, D. S. Ivanov, T. C. Truong, I. Verpoest, F. Baudry, K. Vanden Bosche, H. Xie, Experimental methodology of study of damage initiation and development in textile composites in uniaxial tensile test, Composites Science and Technology 68 (12) (2008) 2340-2349. doi:10.1016/j.compscitech.2007.07.005.

[5] A. R. Melro, Analytical and numerical modelling of damage and fracture of advanced composites, Ph.D. thesis, Universidade do Porto (2011).

[6] S. Daggumati, E. Voet, W. Van Paepegem, J. Degrieck, J. Xu, S. V. Lomov, I. Verpoest, Local strain in a 5-harness satin weave 
composite under static tension: Part I - Experimental analysis, Composites Science and Technology 71 (8) (2011) 1171-1179. doi:10.1016/j.compscitech.2011.03.021.

[7] G. Nilakantan, M. Keefe, E. D. Wetzel, T. A. Bogetti, J. W. Gillespie Jr., Effect of statistical yarn tensile strength on the probabilistic impact response of woven fabrics, Composites Science and Technology 72 (2) (2012) 320-329. doi:10.1016/j.compscitech.2011.11.021.

[8] N. K. Naik, P. Shrirao, B. C. K. Reddy, Ballistic impact behaviour of woven fabric composites: Formulation, International Journal of Impact Engineering 32 (9) (2006) 1521-1552. doi:10.1016/j.ijimpeng.2005.01.004.

[9] G. Reyes, U. Sharma, Modeling and damage repair of woven thermoplastic composites subjected to low velocity impact, Composite Structures 92 (2) (2010) 523-531. doi:10.1016/j.compstruct.2009.08.038.

[10] L. Iannucci, M. L. Willows, An energy based damage mechanics approach to modelling impact onto woven composite materialsPart I: Numerical models, Composites Part A: Applied Science and Manufacturing 37 (11) (2006) 2041-2056. doi:10.1016/j.compositesa.2005.12.013.

[11] L. Iannucci, M. L. Willows, An energy based damage mechanics approach to modelling impact onto woven composite materials: Part II. Experimental and numerical results, Composites Part A: Applied Science and Manufacturing 38 (2) (2007) 540-554. doi:10.1016/j.compositesa.2006.02.023. 
[12] O. Cousigné, D. Moncayo, D. Coutellier, P. Camanho, H. Naceur, Numerical modeling of nonlinearity, plasticity and damage in CFRP-woven composites for crash simulations, Composite Structures 115 (2014) 7588. doi:10.1016/j.compstruct.2014.04.017.

[13] S. Daggumati, W. Van Paepegem, J. Degrieck, J. Xu, S. V. Lomov, I. Verpoest, Local damage in a 5-harness satin weave composite under static tension: Part II - Meso-FE modelling, Composites Science and Technology 70 (13) (2010) 1934-1941. doi:10.1016/j.compscitech.2010.07.002.

[14] A. R. Melro, P. P. Camanho, F. M. Andrade Pires, S. T. Pinho, Numerical simulation of the non-linear deformation of 5-harness satin weaves, Computational Materials Science 61 (2012) 116-126. doi:10.1016/j.commatsci.2012.04.010.

[15] E. Obert, F. Daghia, P. Ladevèze, L. Ballere, Micro and meso modeling of woven composites: Transverse cracking kinetics and homogenization, Composite Structures 117 (2014) 212-221. doi:10.1016/j.compstruct.2014.06.035.

[16] M. Zako, Y. Uetsuji, T. Kurashiki, Finite element analysis of damaged woven fabric composite materials, Composites Science and Technology 63 (34) (2003) 507-516. doi:10.1016/S0266-3538(02)00211-7.

[17] P. Boisse, B. Zouari, A. Gasser, A mesoscopic approach for the simulation of woven fibre composite forming, Composites Science and Technology 65 (34) (2005) 429-436. doi:10.1016/j.compscitech.2004.09.024. 
[18] E. M. Parsons, T. Weerasooriya, S. Sarva, S. Socrate, Impact of woven fabric: Experiments and mesostructure-based continuum-level simulations, Journal of the Mechanics and Physics of Solids 58 (11) (2010) 1995-2021. doi:10.1016/j.jmps.2010.05.006.

[19] H. E. Johnson, L. A. Louca, S. Mouring, A. S. Fallah, Modelling impact damage in marine composite panels, International Journal of Impact Engineering 36 (1) (2009) 25-39. doi:10.1016/j.ijimpeng.2008.01.013.

[20] P. Navarro, J. Aubry, S. Marguet, J. F. Ferrero, S. Lemaire, P. Rauch, Semi-continuous approach for the modeling of thin woven composite panels applied to oblique impacts on helicopter blades, Composites Part A: Applied Science and Manufacturing 43 (6) (2012) 871-879. doi:10.1016/j.compositesa.2012.01.020.

[21] P. Navarro, J. Aubry, S. Marguet, J. F. Ferrero, S. Lemaire, P. Rauch, Experimental and numerical study of oblique impact on woven composite sandwich structure: Influence of the firing axis orientation, Composite Structures 94 (6) (2012) 1967-1972. doi:10.1016/j.compstruct.2012.02.001.

[22] F. Pascal, P. Navarro, S. Marguet, J.-F. Ferrero, On the modelling of low to medium velocity impact onto woven composite materials with a $2 \mathrm{~d}$ semi-continuous approach, Composite Structures 134 (2015) 302-310. doi:10.1016/j.compstruct.2015.08.067.

[23] J.-L. Batoz, G. Dhatt, Modélisation des structures par éléments finis: Coques, hermes Edition, Vol. 3, Paris, 1992. 
[24] G. A. O. Davies, D. Hitchings, J. Ankersen, Predicting delamination and debonding in modern aerospace composite structures, Composites Science and Technology 66 (6) (2006) 846-854. doi:10.1016/j.compscitech.2004.12.043.

[25] F. Aymerich, F. Dore, P. Priolo, Simulation of multiple delaminations in impacted cross-ply laminates using a finite element model based on cohesive interface elements, Composites Science and Technology 69 (1112) (2009) 1699-1709. doi:10.1016/j.compscitech.2008.10.025.

[26] S. Bianchi, A. Corigliano, R. Frassine, M. Rink, Modelling of interlaminar fracture processes in composites using interface elements, Composites Science and Technology 66 (2) (2006) 255-263. doi:10.1016/j.compscitech.2005.04.034.

[27] P. Ladevèze, O. Allix, J.-F. Deü, D. Lévêque, A mesomodel for localisation and damage computation in laminates, Computer Methods in Applied Mechanics and Engineering 183 (12) (2000) 105-122. doi:10.1016/S0045-7825(99)00214-5. 


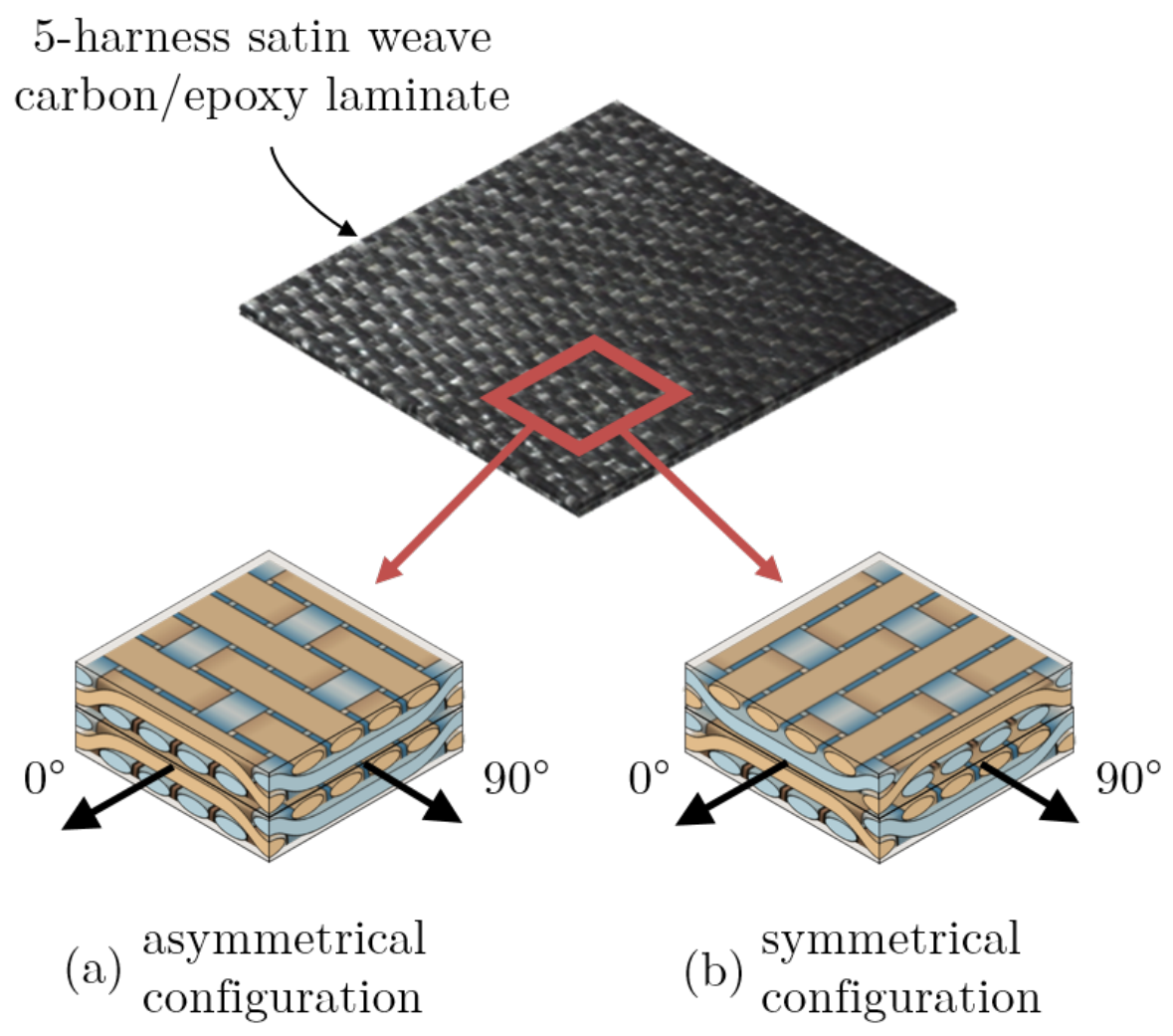

Figure 1: Two stacking configuration of a 5 -harness satin woven laminate made of two plies oriented at (0/90): (a) asymmetrical and (b) symmetrical distribution of tows about the neutral axis of the laminate. 


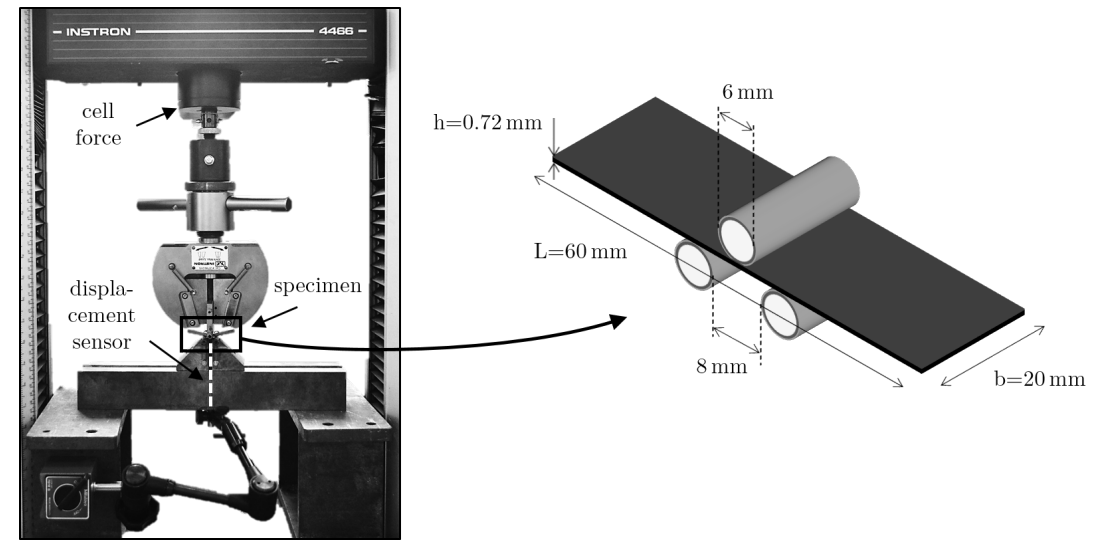

Figure 2: Three-point bending test set up and specimen dimensions. 

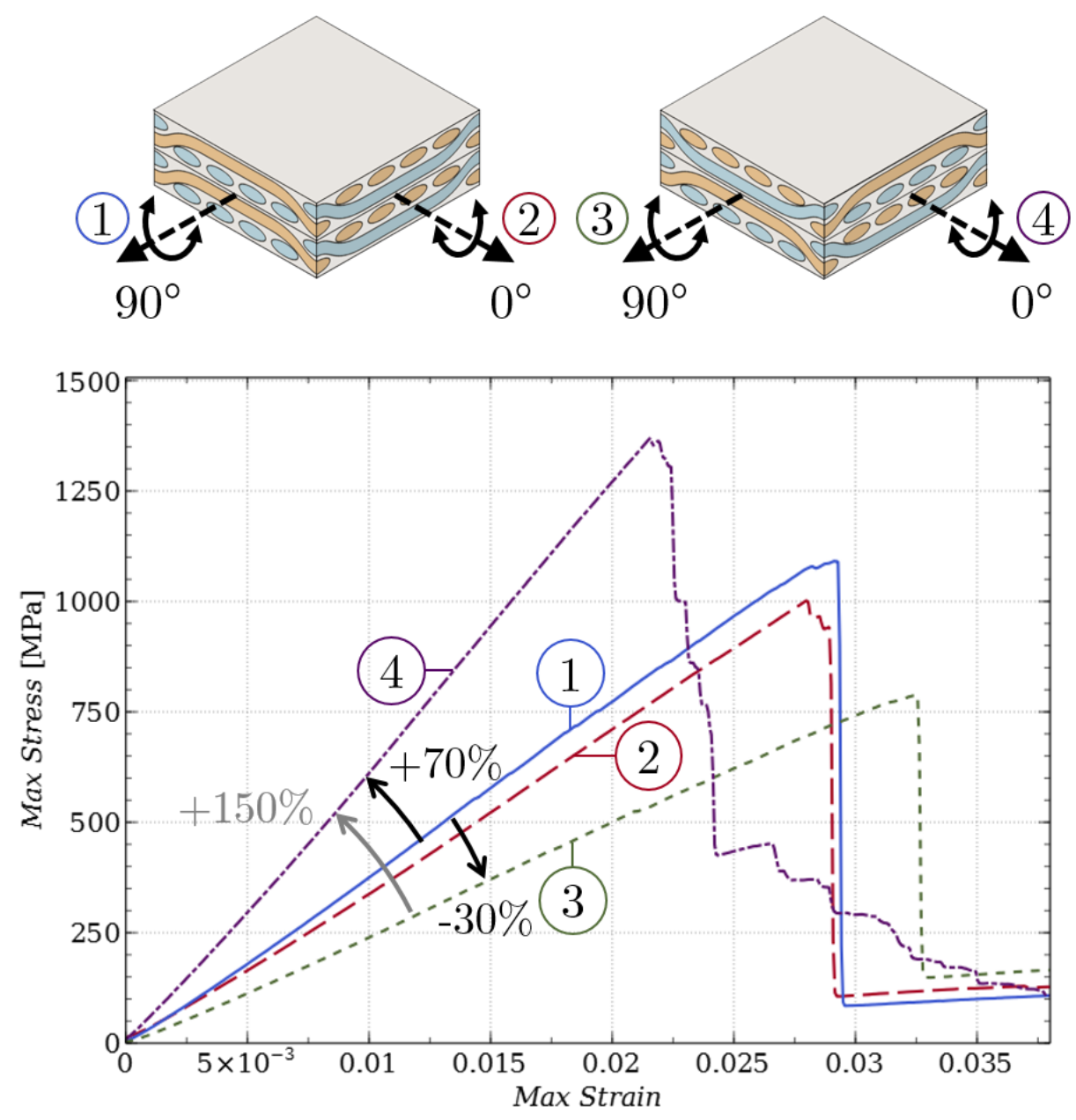

Figure 3: Max stress/Max strain curves for the three point bending test. 


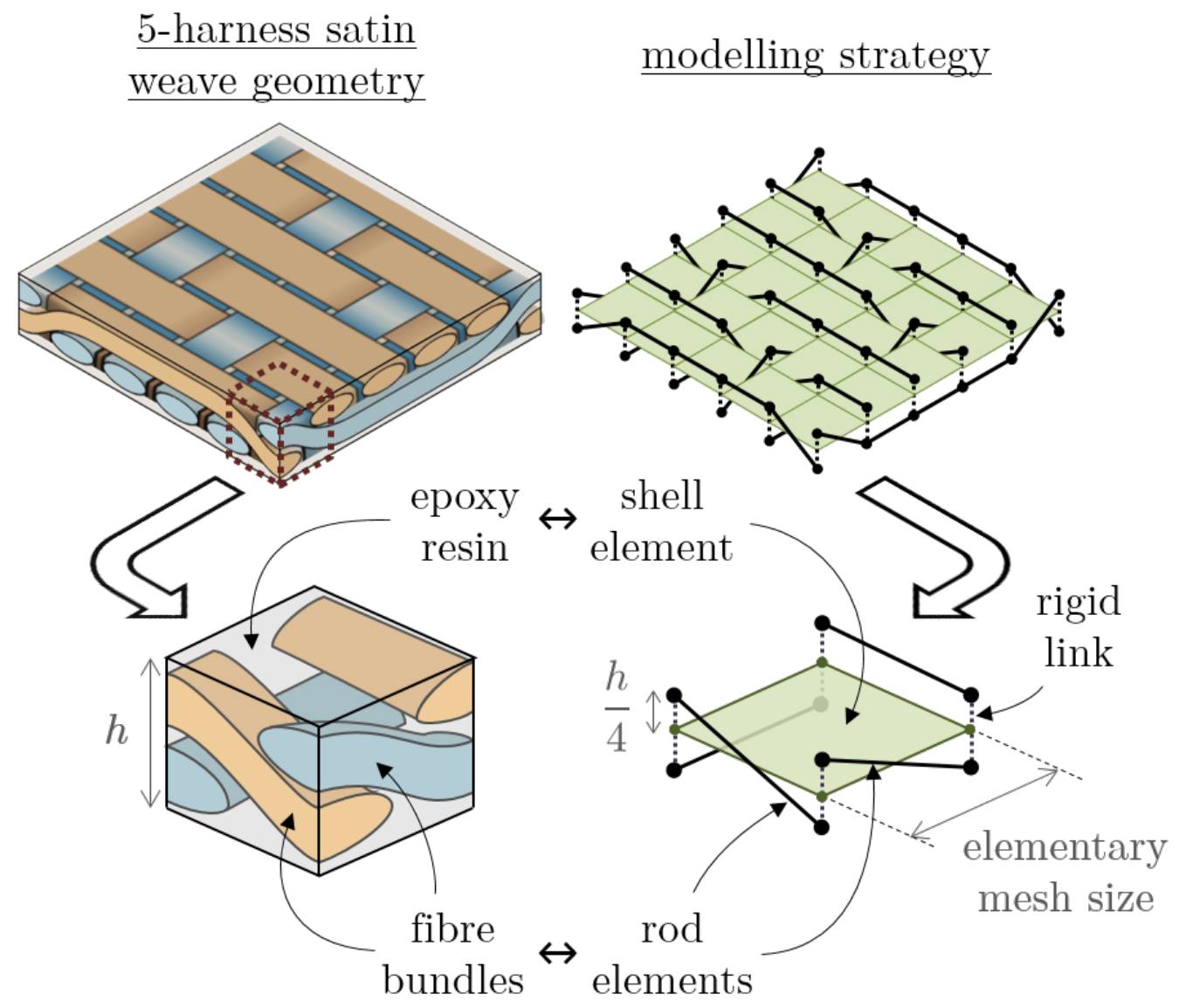

Figure 4: Principle of the modeling strategy through the schematic (left) and the numerical (right) representation of the unit-cell (top) and the elementary-cell (bottom) of a 5-harness satin woven composite material. 


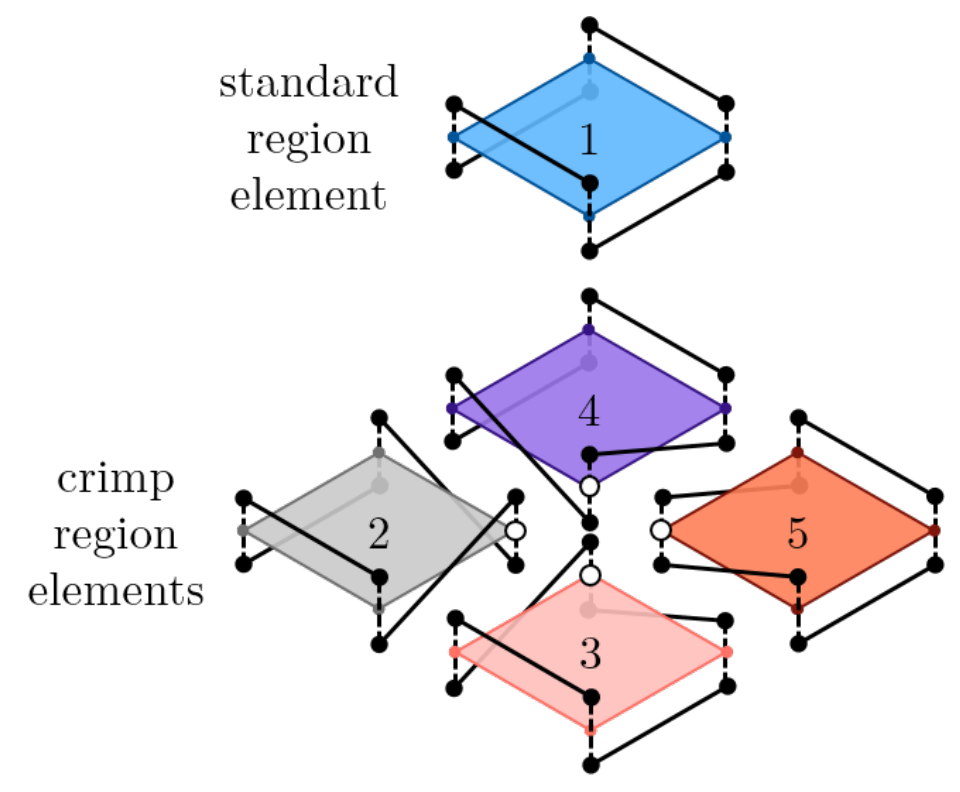

(a) fundamental element configurations

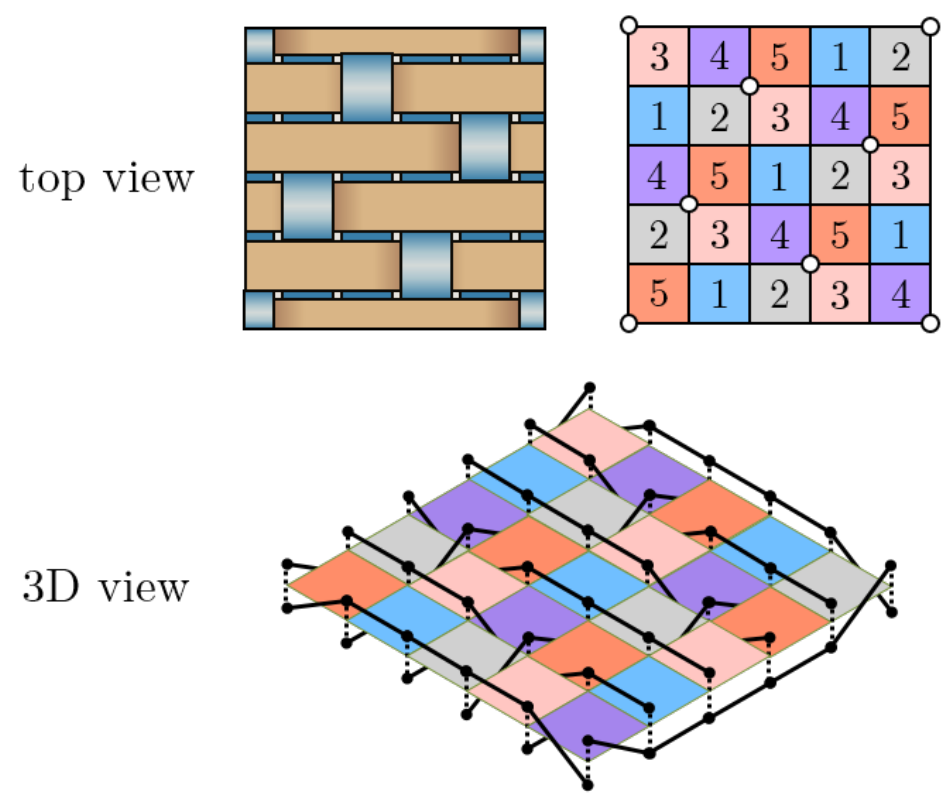

(b) 5-harness satin weave meshing

Figure 5: Modeling implementation: (a) fundamental elements configurations and (b) meshing of a 5-harness satin weave pattefn using the five element configurations. 


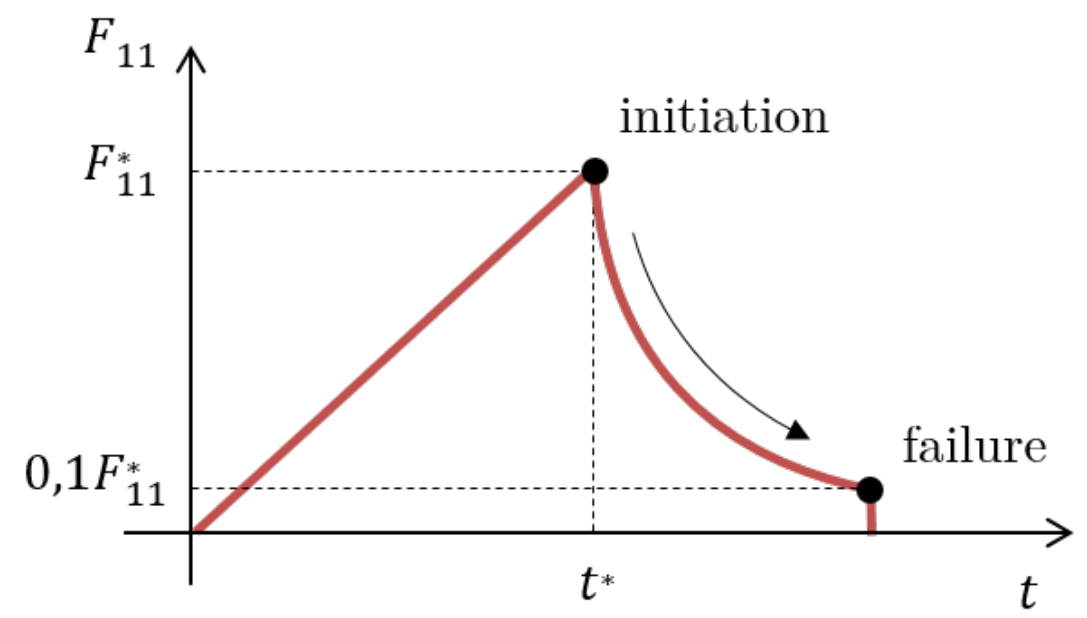

Figure 6: Brittle failure of the rods with an exponential decreasing law.

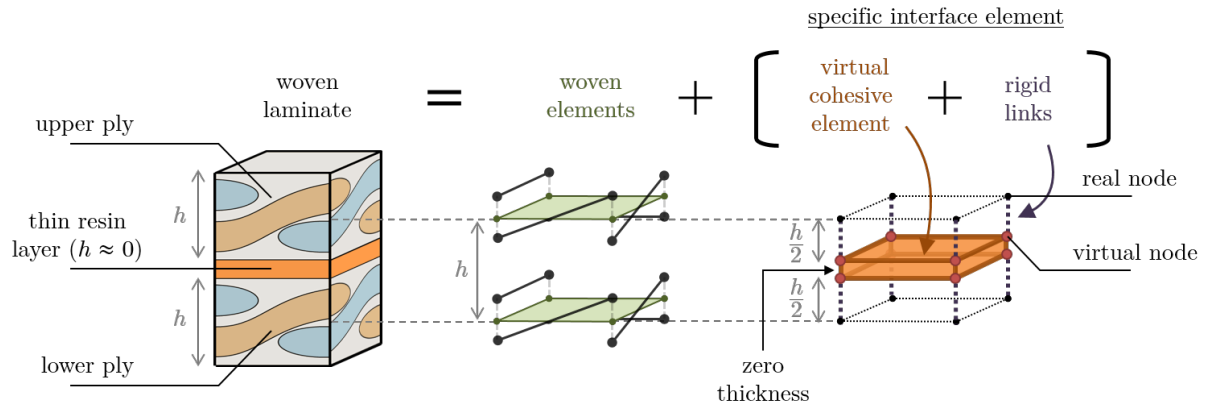

Figure 7: Principle of the developed interface element. 


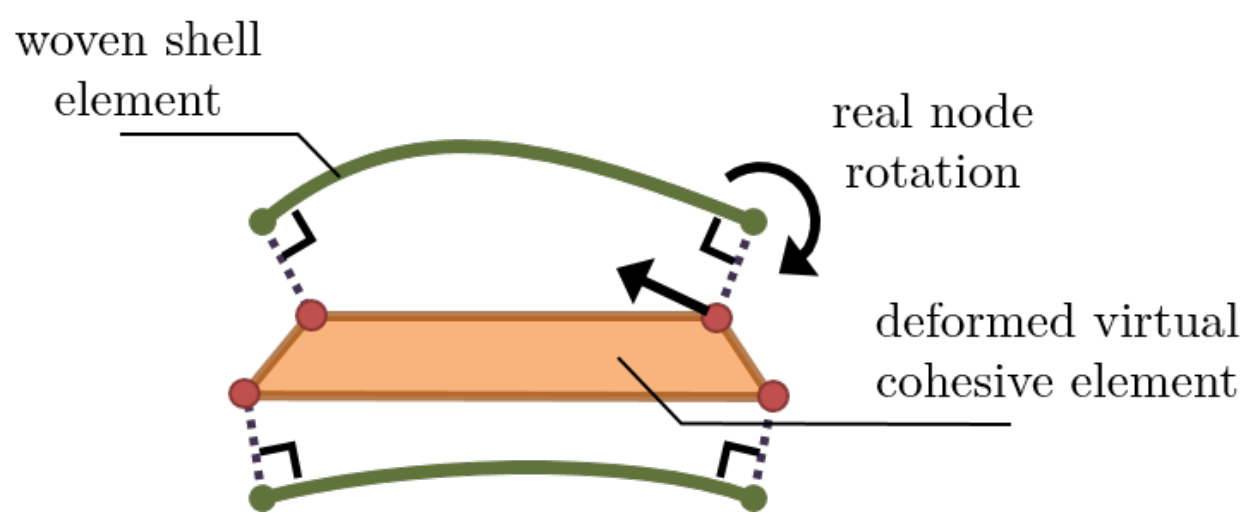

Figure 8: Behavior of the developed interface element.

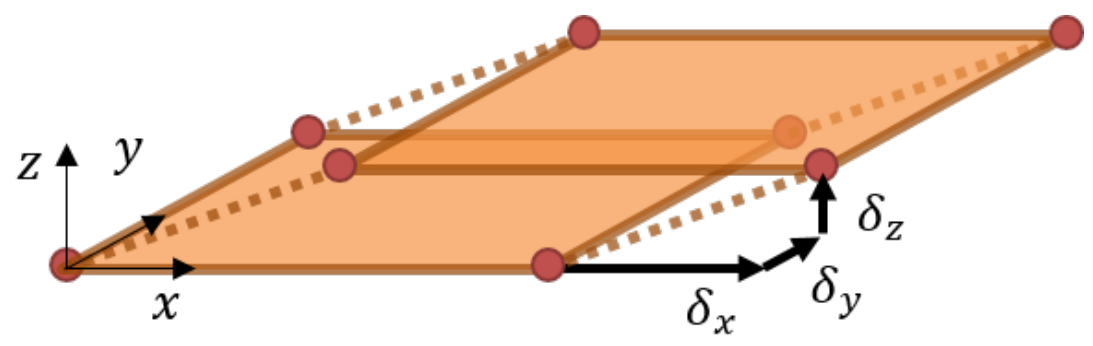

Figure 9: Definition of the displacement discontinuities considered. 


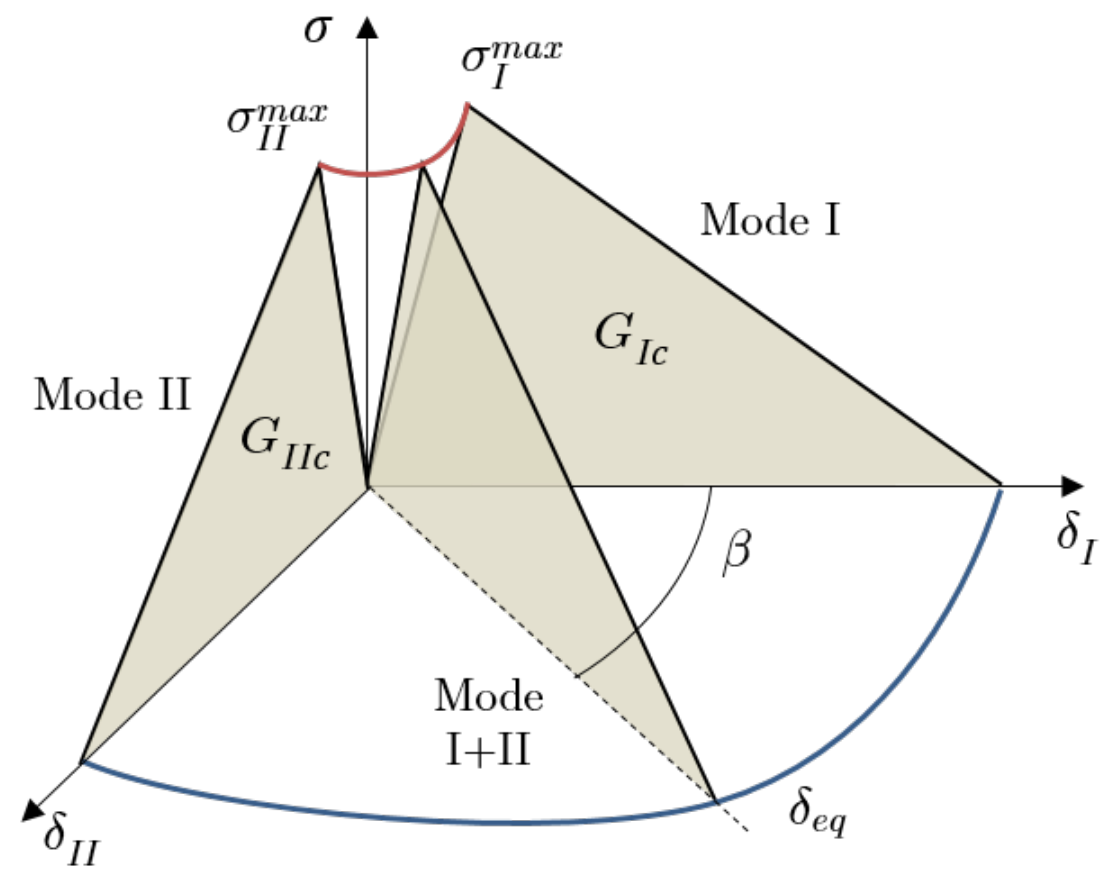

Figure 10: Bilinear traction-separation law for the developed interface. 


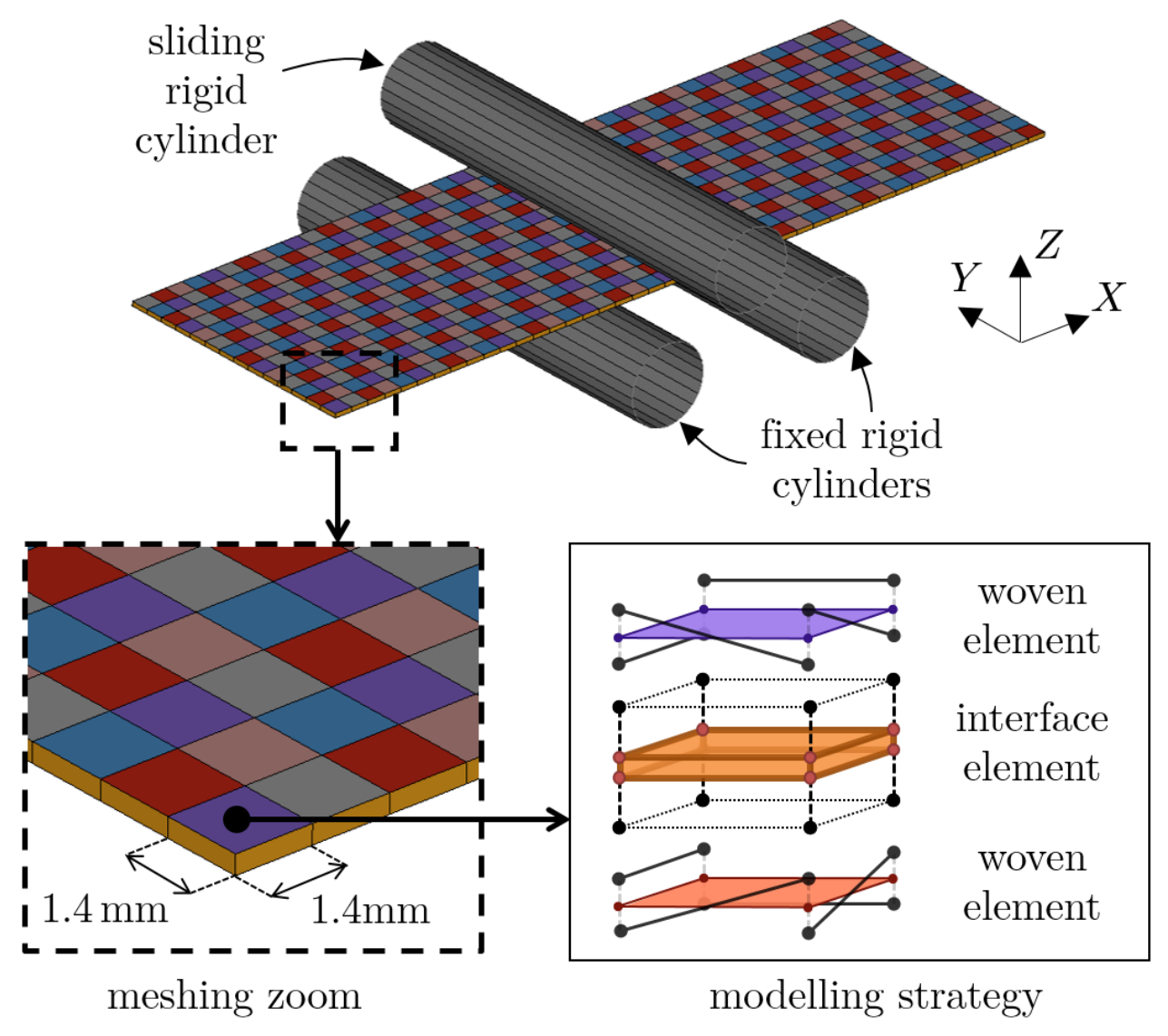

Figure 11: Three-point bending specimen modelling. 

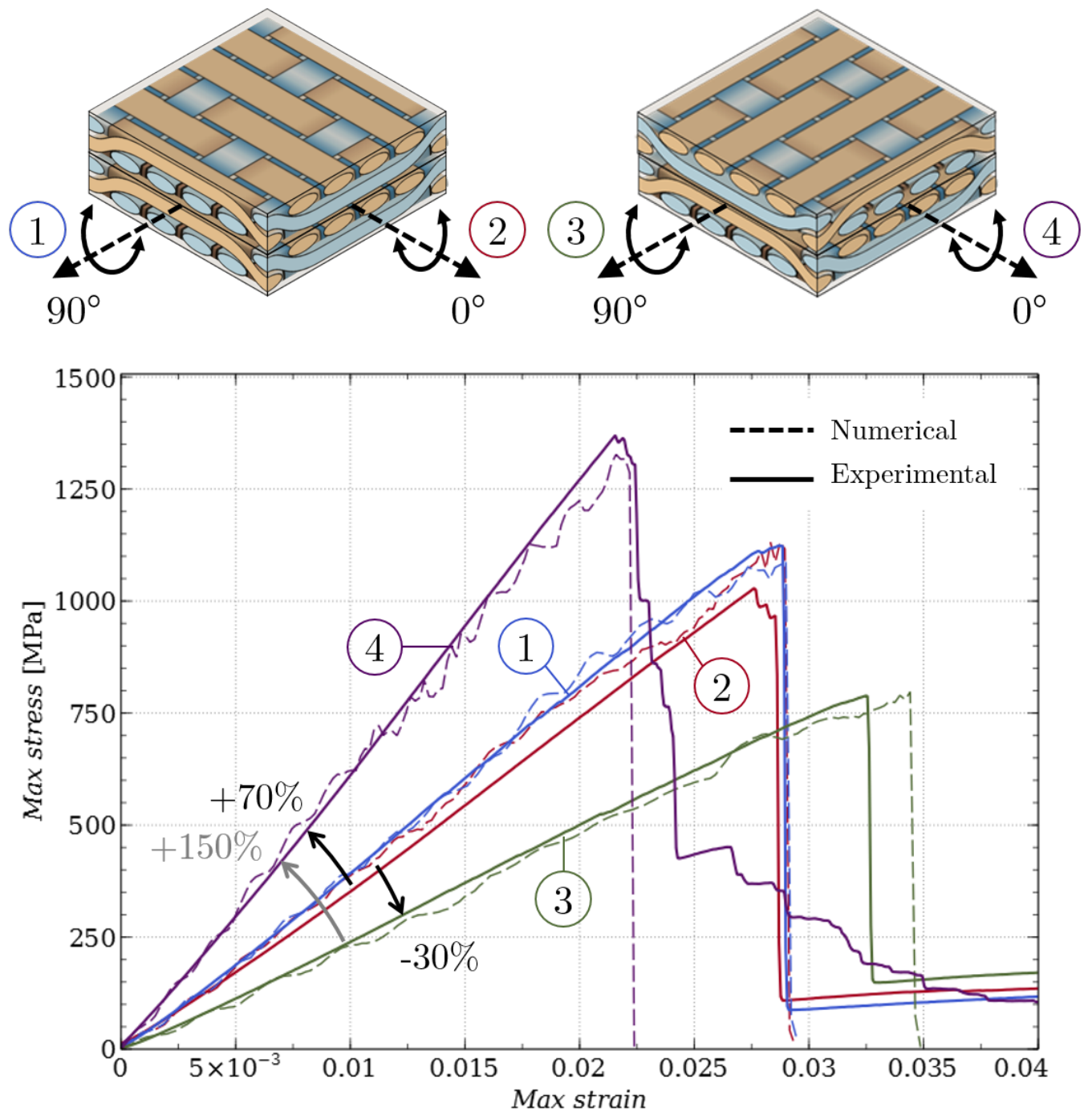

Figure 12: Results of the three-point bending test. 


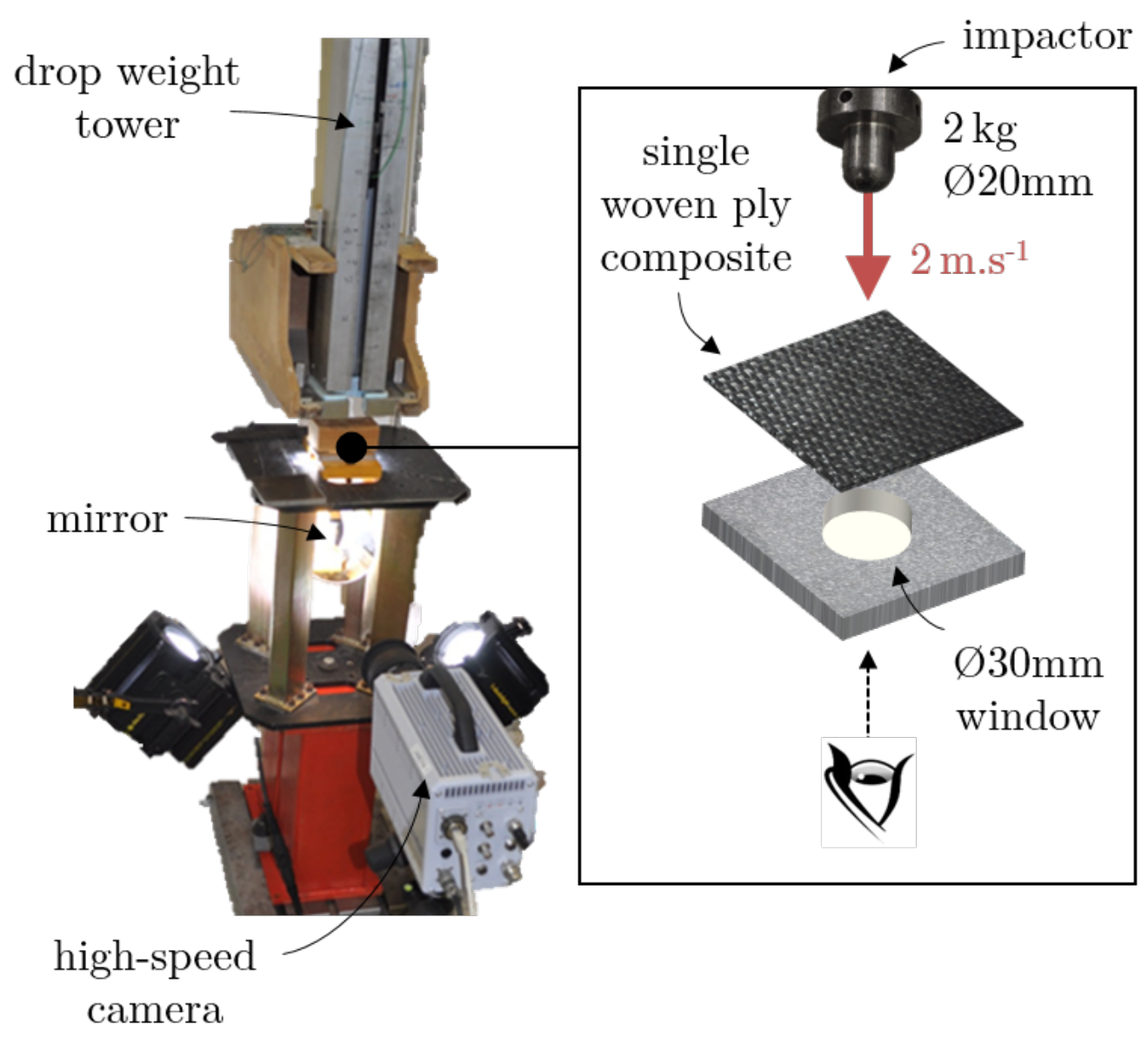

Figure 13: Experimental set up of drop weight impact test. 


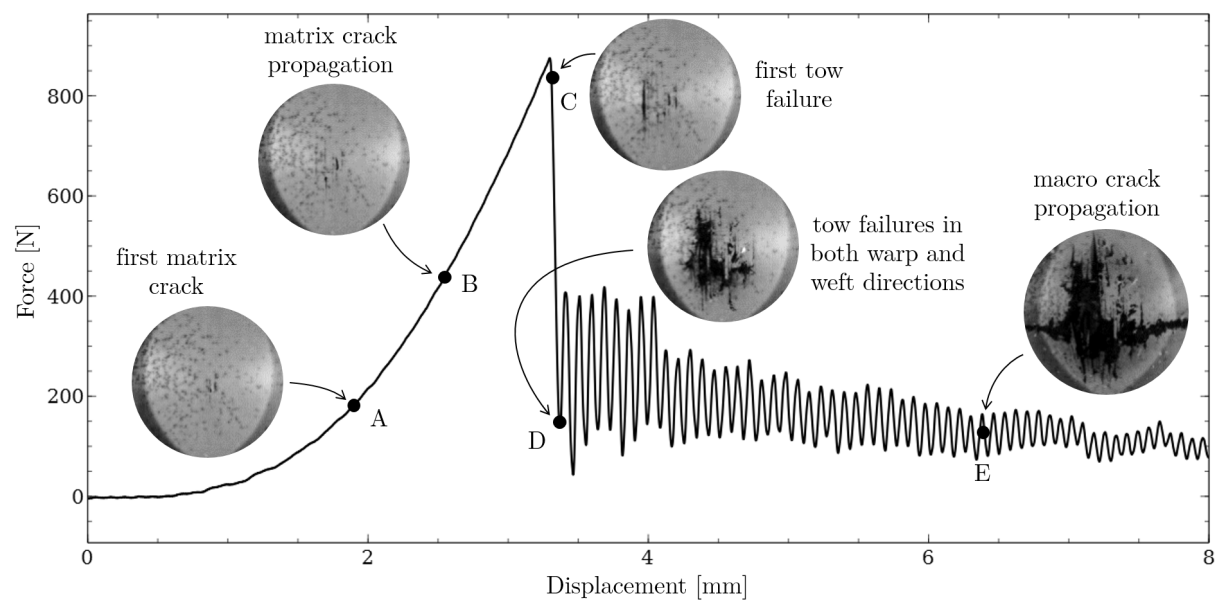

Figure 14: Experimental load versus displacement curve.
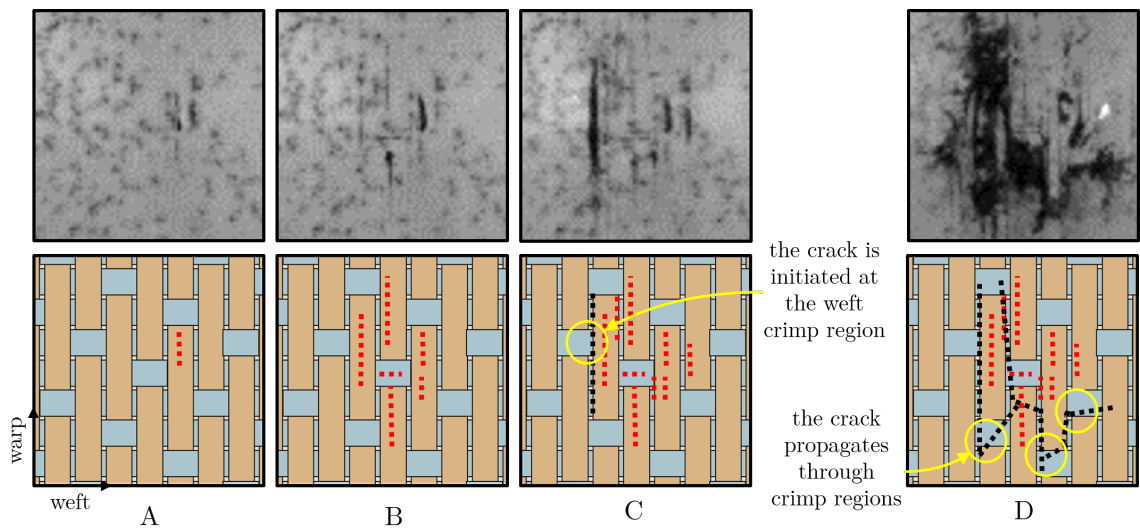

the crack is
initiated at

the weft

crimp region

the crack

propagates

through

crimp regions

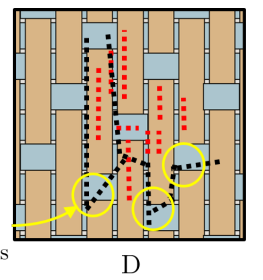

Figure 15: Damage scenario analysis from experimental observation. 


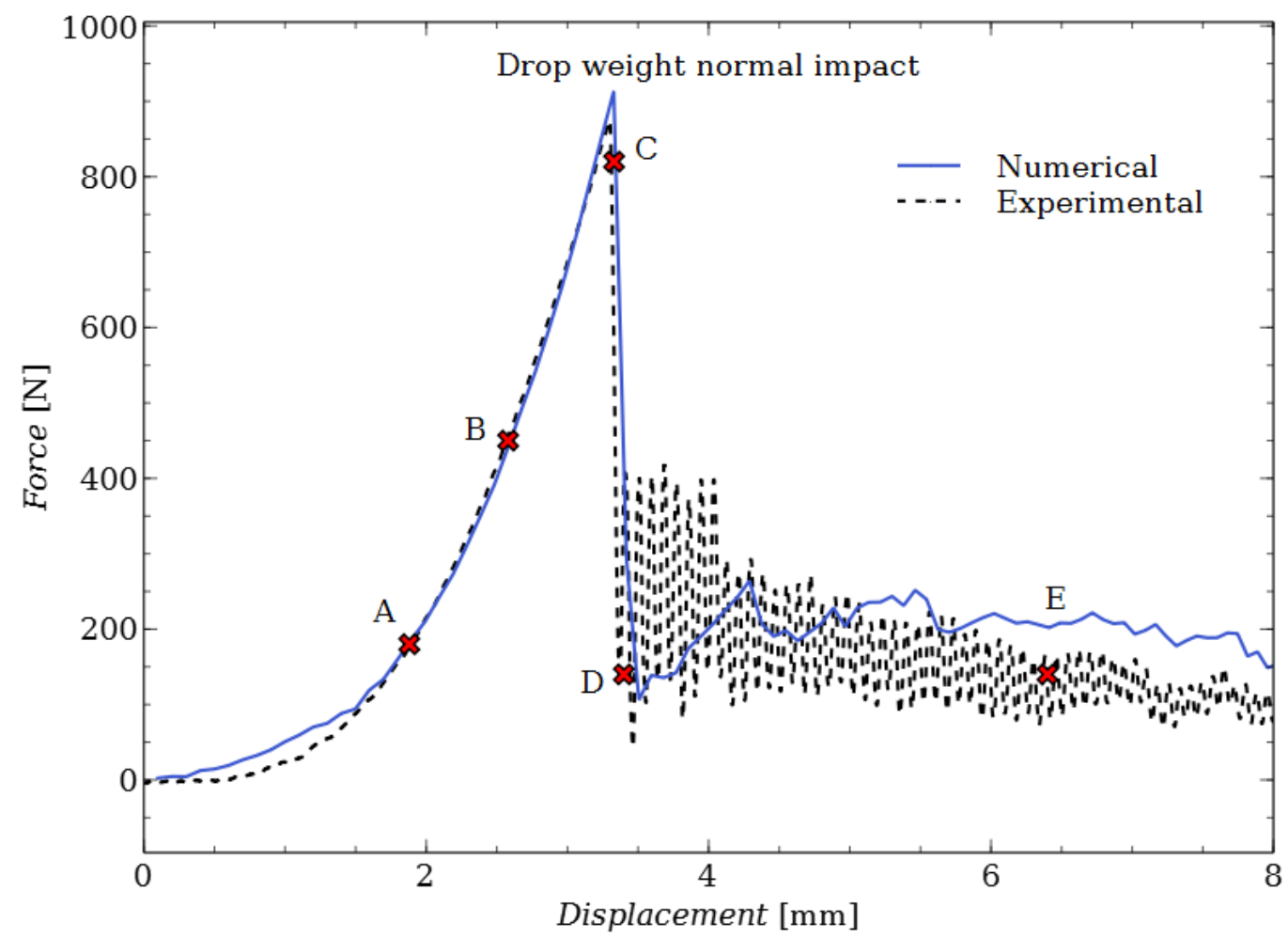

Figure 16: Experimental and numerical load versus displacement curves of the drop weight impact test. 


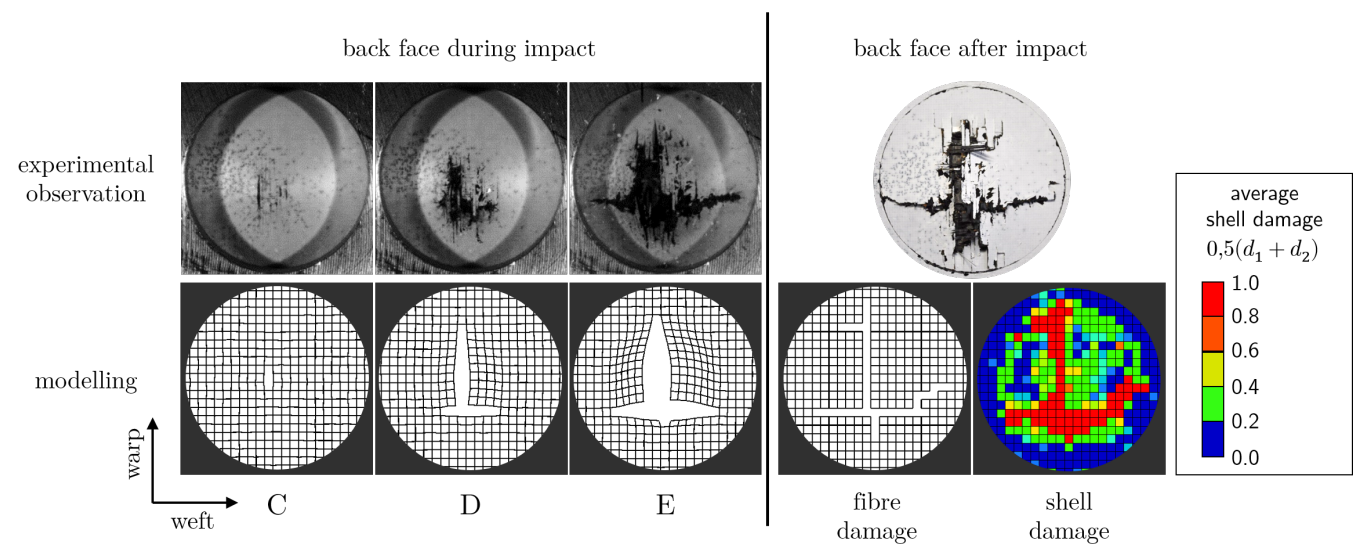

Figure 17: Experimental and numerical fibre damage evolution during the drop weight impact test.

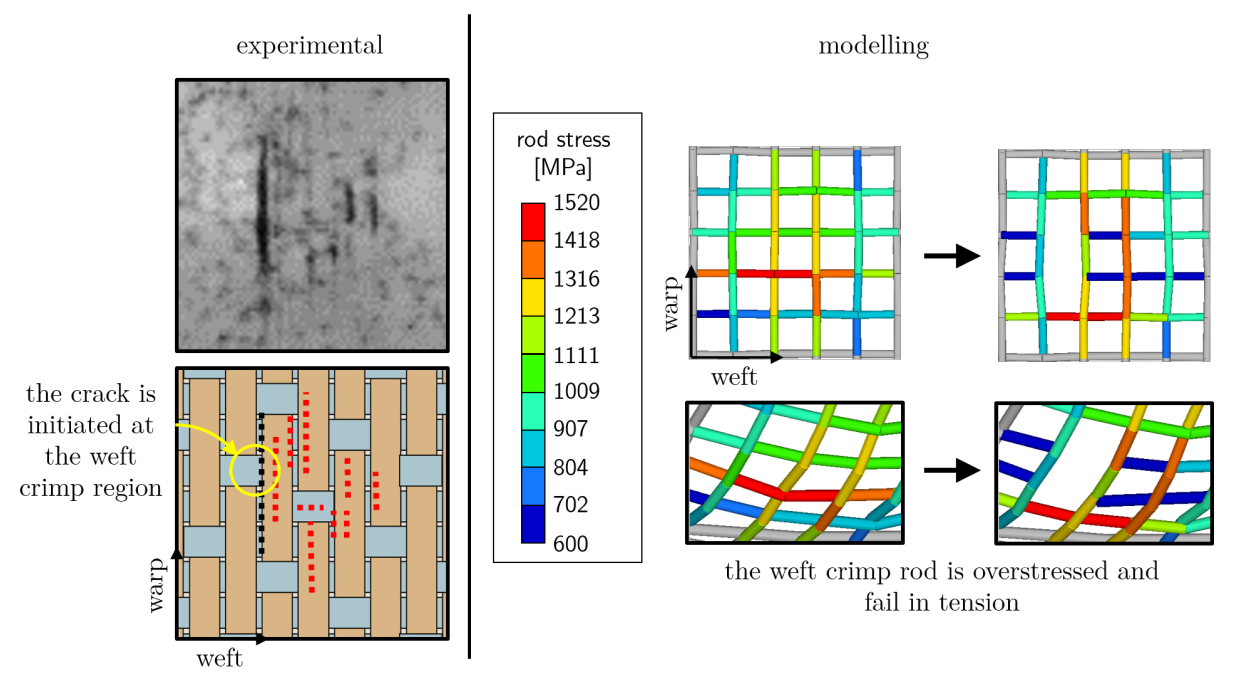

Figure 18: Analysis of the first fibre rupture. 
Table 1: Identified parameters for the shell elements

\begin{tabular}{llllll}
\hline \multicolumn{2}{c}{ Shell elasticity } & & \multicolumn{2}{l}{ In-plane shear plasticity } & \multicolumn{2}{c}{ Shell damage } \\
\hline$E(\mathrm{MPa})$ & 4500 & $G_{12}(\mathrm{MPa})$ & 2500 & $Y_{0}(\mathrm{~J})$ & 1.5 \\
$G_{i 3}(\mathrm{MPa})$ & 4000 & $\sigma_{0}(\mathrm{MPa})$ & 80 & $Y_{c}(\mathrm{~J})$ & 0.4 \\
$\nu$ & 0.3 & $K_{\text {plas }}(\mathrm{MPa})$ & 120 & $\gamma_{\text {max }}^{p}$ & 0.07 \\
& $B$ & 0.5 & & \\
\hline
\end{tabular}

Table 2: Identified parameters for the bilinear cohesive law

\begin{tabular}{llll}
\hline Initiation & \multicolumn{3}{c}{ Propagation } \\
\hline$\sigma_{I}^{\max }$ & $40 \mathrm{MPa}$ & $G_{I c}$ & $0.56 \mathrm{~kJ}$ \\
$\sigma_{I I}^{\max }$ & $60 \mathrm{MPa}$ & $G_{I I c}$ & $1.6 \mathrm{~kJ}^{-2} \mathrm{~mm}^{-2}$ \\
\hline
\end{tabular}

